\title{
Antioxidant enzyme activities in rabbits under oxidative stress induced by high fat diet
}

\author{
Marta Skowron ${ }^{1}$, Jolanta Zalejska-Fiolka ${ }^{1}$, Urszula Błaszczyk ${ }^{1}$, \\ Ewa Chwalińska ${ }^{1}$, Aleksander Owczarek ${ }^{2}$, Ewa Birkner ${ }^{1}$ \\ ${ }^{1}$ Department of Biochemistry, School of Medicine with the Division of Dentistry in Zabrze, \\ ${ }^{2}$ Department of Instrumental Analysis, School of Pharmacy with the Division of Laboratory Medicine in Sosnowiec, \\ Medical University of Silesia, 40-006 Katowice, Poland \\ jzalejskafiolka@sum.edu.pl
}

Received: December 7, 2017 Accepted: May 10, 2018

\begin{abstract}
Introduction: The aim of this study was to investigate whether the type and form of oil (raw/non-oxidised (N) or postfrying/oxidised (O)) consumed in high-fat diets affect the oxidative status of an organism, as observed by malondialdehyde (MDA) concentration as an oxidative factor and antioxidant enzyme activity. Material and Methods: Fats in the diet came from rapeseed oil $(\mathrm{R})$ and olive oil $(\mathrm{O})$. Results: The applied diet caused a decrease in MDA concentration $(\mu \mathrm{mol} / \mathrm{L})$ in serum in group $\mathrm{RN}$ from $2.94 \pm 0.87$ to $1.76 \pm 0.13$, in group $\mathrm{ON}$ from $2.45 \pm 0.62$ to $1.50 \pm 0.10$, and in group $\mathrm{OO}$ from $2.70 \pm 1.16$ to $1.84 \pm 0.36$. Meanwhile, MDA concentration (mmol/L) increased in blood haemolysate in group RO from $0.15 \pm 0.07$ to $0.22 \pm 0.03$ and in group $\mathrm{OO}$ from $0.17 \pm 0.02$ to $0.22 \pm 0.02$. The observed changes caused a response of the enzymatic antioxidant system in both models, especially followed by an increase in activities of total superoxide dismutase and its mitochondrial isoenzyme in all experimental groups, while its cytosolic isoenzyme activity increased only in ON and OO groups. Increased activity of glutathione peroxidase (GPX) in groups RN and RO and of catalase (CAT) in groups ON and OO was observed. Significant differences in responses to the different types and forms of oils were probably caused by the different oxidative stability of the studied oils. Conclusion: This diet disturbed the body's oxidative status; however, during the six-month study the enzymatic antioxidant system remained effective.
\end{abstract}

Keywords: rabbit, oil, antioxidant enzymes, MDA, oxidative stress.

\section{Introduction}

The proper amount and form (raw/non-oxidised) of vegetable oils with an optimal ratio of omega 3 to omega 6 fatty acids are essential aspects of a wellbalanced diet and factors for the sufficient development of an organism. However, consumption of excessive amounts of fats (even vegetable) in either non-oxidised or oxidised form in a high-fat diet (HFD) may be an oxidative stress inductor, which in turn may damage proteins, lipids, and carbohydrates and causes many diseases $(2,10,20)$. Nevertheless, due to different amounts of unsaturated fatty acids and non-enzymatic antioxidants in the composition of oils, consumption of one oil may promote oxidative stress to a greater or lesser extent than consumption of another $(5,6,21)$.
To determine the oxidative status of an organism, it is necessary to determine the relationship between oxidant and antioxidant parameters in the body. Since lipid peroxidation is one of the most predominant and recognised consequences of intensified generation of free radicals, oxidative stress can be evaluated based on concentration of malondialdehyde (MDA), the main product of lipid peroxidation $(4,9)$. The largest role in the antioxidant activity of a body is played by the enzymatic system, which includes the following enzymes: total superoxide dismutase (SOD) and its isoenzymes: cytosolic (CuZnSOD) and mitochondrial (MnSOD), catalase (CAT), and glutathione peroxidase (GPX). SOD is the only enzyme decomposing hydrogen peroxide $\left(\mathrm{H}_{2} \mathrm{O}_{2}\right)$ to the superoxide anion radical $\left(\mathrm{O}_{2}^{-}\right)$. This reaction requires the combined 
effects CAT and GPX which decompose $\mathrm{H}_{2} \mathrm{O}_{2}$, CAT doing so at high and GPX at low concentrations of $\mathrm{H}_{2} \mathrm{O}_{2}$ (18).

In addition to enzymatic antioxidative factors, the protective system also comprises non-enzymatic antioxidants soluble in water and fats, such as vitamin $\mathrm{E}, \beta$-carotene, and vitamin $\mathrm{C}$, polyphenols or other compounds such as squalene. They are delivered through a suitable diet and improve the body's enzymatic antioxidant system $(7,23)$. One way of supplying these components is consuming vegetable oils.

The aim of the study was to investigate whether the type and form of oil (raw or oxidised) consumed affect the oxidative status of an organism, as observed by the MDA concentration and antioxidant enzyme activity.

\section{Material and Methods}

Preparation of oil samples. Rapeseed oil and olive oil were purchased from a local supermarket. For oil oxidation, $1 \mathrm{~L}$ of the oil was heated to $180^{\circ} \mathrm{C}$ for six hours (mixed, with air access). The extent of oxidation was determined by the peroxide (PV) and iodine (JV) values as suggested by the Polish Committee for Standardisation (15) and by a chromatographic method to measure the content of fatty acids (FA) (26).

Animals. The study was conducted under the guidelines of the Animal Care Committee of the University of Silesia. It was assigned the approval number KNW-022/LKE-1-25/08 and lasted six months. In total, 32 male Chinchilla rabbits (b.w. 2,800 $\pm 200 \mathrm{~g}$ ) were obtained from the Centre for Experimental Medicine of the Medical University of Silesia in Katowice. The animals were housed individually in stainless steel metabolic cages under a $12 \mathrm{~h} \mathrm{light/dark}$ cycle. They were fed $80 \mathrm{~g}$ of proper fodder $/ \mathrm{kg} \mathrm{b} . \mathrm{w} . / 24 \mathrm{~h}$ and allowed water ad libitum. The animals were weighed weekly throughout the duration of the experiment. The fodder was provided once daily. Feed intake was assessed by evaluating the leftover feed. The amount of additives was calculated by the weight of the animal and modified during the experiment.

The rabbits were divided into four equal groups according to the following scheme:

$\mathrm{RN}$ - rabbits fed basal diet (BD) supplemented with $10 \%$ non-oxidised rapeseed oil;

RO - rabbits fed BD supplemented with $10 \%$ oxidised rapeseed oil;

$\mathrm{ON}$ - rabbits fed BD supplemented with $10 \%$ nonoxidised olive oil;

OO - rabbits fed BD supplemented with $10 \%$ oxidised olive oil.

The diets for each group were prepared weekly and stored in a refrigerator at $4^{\circ} \mathrm{C}$. The $\mathrm{BD}$ was composed of protein, carbohydrate, and fat providing respectively $24 \%, 69 \%$, and $7 \%$ of the total energy content of the diet. Groups fed BD with $10 \%$ oils received respectively: $18 \%$ energy from protein, $39 \%$ from carbohydrate, and $42 \%$ from fat. Basal diet was from the Morawski Feed Mill, Kcynia, Poland.

Sample collection. At the end of the study period the rabbits were sacrificed under anaesthesia with a mixture of $50 \mathrm{mg} / \mathrm{kg} \mathrm{b}$.w. of ketamine, $0.1 \mathrm{mg} / \mathrm{kg} \mathrm{b} . \mathrm{w}$. of fentanyl, and $0.1 \mathrm{mg} / \mathrm{kg}$ b.w. of droperidol administered intramuscularly following a $12 \mathrm{~h}$ fasting. The livers were collected for biochemical study after isotonic saline rinsing.

Biochemical examination. The concentration of MDA was determined in serum (shown in results as S-MDA) and blood haemolysate (shown in results as L-MDA). The activities of SOD, MnSOD, and $\mathrm{CuZnSOD}$ were determined in serum and are denoted in results by S-SOD, S-MnSOD, and S-CuZnSOD. The activities of CAT, GPX, and glutathione reductase (GR) were determined in blood haemolysate and have the descriptors L-CAT, L-GPX, and L-GR in the results. Serum was obtained by centrifuging the blood at 3,000 rpm for $10 \mathrm{~min}$ at $4^{\circ} \mathrm{C}$. On the day the blood was taken, blood haemolysate was prepared from centrifuged blood cells after centrifugation as mentioned above. The sediment of erythrocytes was rinsed three times with saline and then haemolysed with deionised water. Determination of the haemoglobin $(\mathrm{Hb})$ concentration was carried out in 10\% haemolysate, using Drabkin's cyanomethaemoglobin method (22). The Oyanagui method was used to determine the activities of SOD, MnSOD, and CuZnSOD (EC 1.15.1.1) (13). Enzymatic activity was expressed in nitrite units per millilitre $(\mathrm{NU} / \mathrm{mL})$. In this method one nitrite unit (NU) means $50 \%$ inhibition by SOD of nitrite ion production. The activity of CAT (EC 1.11.1.6) was determined by the kinetic method described by Aebi (1). Glutathione peroxidase (EC 1.11.1.9) activity was measured by the kinetic method according to Paglia and Valentine (14). The activity of GR was determined according to Richterich (16). Data for all activities are shown in international units/g $\mathrm{Hb}(\mathrm{kIU} / \mathrm{gHb})$. The MDA concentration was determined spectrofluorimetrically in serum (S-MDA) and blood haemolysate (L-MDA), using its reactivity with thiobarbituric acid according to Ohkawa et al. (12). Data were reported as $\mu \mathrm{mol} / \mathrm{L}$ in serum and $\mathrm{mmol} / \mathrm{L}$ in haemolysate.

Statistical analysis. Statistical analysis was performed using STATISTICA 10.0 PL software (StatSoft, Poland). Data were presented as mean value \pm standard deviation and their normality was checked with the Shapiro-Wilk test, based on data histogram and quantile-quantile plots. Homogeneity of variance was tested by the Levene test. In all cases, data distributions met normality assumptions. In order to check statistical hypothesis, two-way ANOVA was used with contrast analysis as post-hoc test. The results are presented in figures showing means with confidence intervals. $\mathrm{P}<0.05$ was taken to be statistically significant. 


\section{Results}

The results are shown in Table 1 and Figs $1-8$.

Oxidised rapeseed oil characterisation. Obtained results were reported in a previous publication (24). We noted an increased content of palmitic and oleic acids and a decreased content of linoleic and linolenic acids after oxidation at $180^{\circ} \mathrm{C}$ for 6 h. During rapeseed oil oxidation, PV increased 106 times and JV decreased by about $2 \%$, and during olive oil oxidation PV increased about $18 \%$ and JV decreased about $3 \%$.

Figures 1 and 2 show changes between profiles of MDA concentrations in serum (S-MDA) and haemolysate (L-MDA) during the experiment. Table 1 gives statistical significance levels (p) for differences between S-MDA and L-MDA concentrations among groups $\mathrm{Q}$ and $\mathrm{D}$ receiving $\mathrm{HFD}$ with different vegetable oil additions.

There were differences between groups RN and $\mathrm{ON}$ (Q3) and RO and OO (Q4) for S-MDA $(\mathrm{P}<0.001)$ and between groups $\mathrm{RN}$ and $\mathrm{RO}(\mathrm{Q} 1), \mathrm{RV}$ and $\mathrm{ON}(\mathrm{Q} 3)$, and $\mathrm{RO}$ and $\mathrm{OO}(\mathrm{Q} 4)$ for L-MDA $(\mathrm{P}<0.01)$. We also observed a significant decrease in S-MDA concentrations in the RN $\left(\mathrm{D}_{1}\right), \mathrm{ON}\left(\mathrm{D}_{2}\right)$, and OO $\left(D_{4}\right)$ groups at the end of the experiment in comparison to the first day $(\mathrm{P}<0.05)$ : in the $\mathrm{RN}$ group from $2.94 \pm 0.87 \mu \mathrm{mol} / \mathrm{L}$ to $1.76 \pm 0.13 \mu \mathrm{mol} / \mathrm{L}$; in the ON group from $2.45 \pm 0.62 \mu \mathrm{mol} / \mathrm{L}$ to 1.50 $\pm 0.10 \mu \mathrm{mol} / \mathrm{L}$; and in the $\mathrm{OO}$ group from 2.70 $\pm 1.16 \mu \mathrm{mol} / \mathrm{L}$ to $1.84 \pm 0.36 \mu \mathrm{mol} / \mathrm{L}$. We also noted a significant increase in L-MDA in the RO $\left(\mathrm{D}_{3}\right)$ and OO $\left(\mathrm{D}_{4}\right)$ groups $(\mathrm{P}<0.01)$ : in the RO group from $0.15 \pm 0.07 \mathrm{mmol} / \mathrm{L}$ to $0.22 \pm 0.03 \mathrm{mmol} / \mathrm{L}$, and in the $\mathrm{OO}$ group from $0.17 \pm 0.03 \mathrm{mmol} / \mathrm{L}$ to 0.22 $\pm 0.02 \mathrm{mmol} / \mathrm{L}$. Other changes were not statistically significant.

\section{MDA concentration}

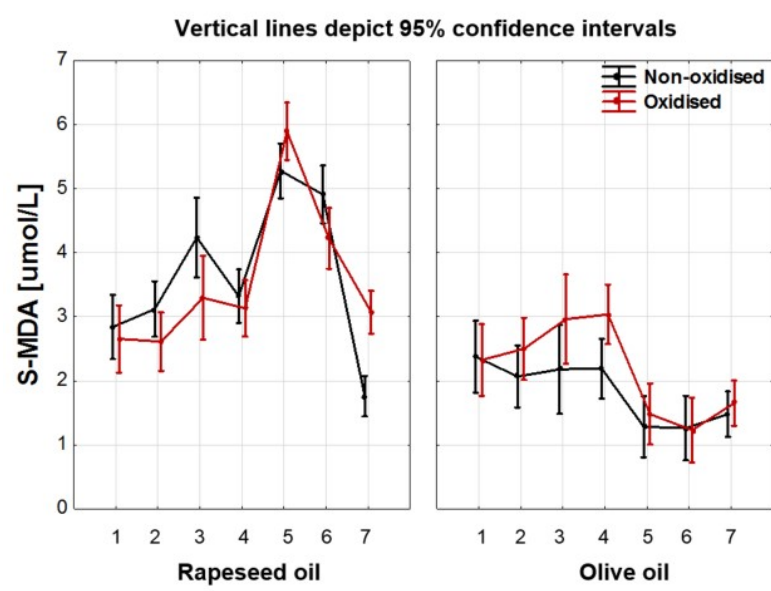

Fig. 1. Concentration of MDA in serum in groups receiving nonoxidised and oxidised rapeseed oil and olive oil during experiment

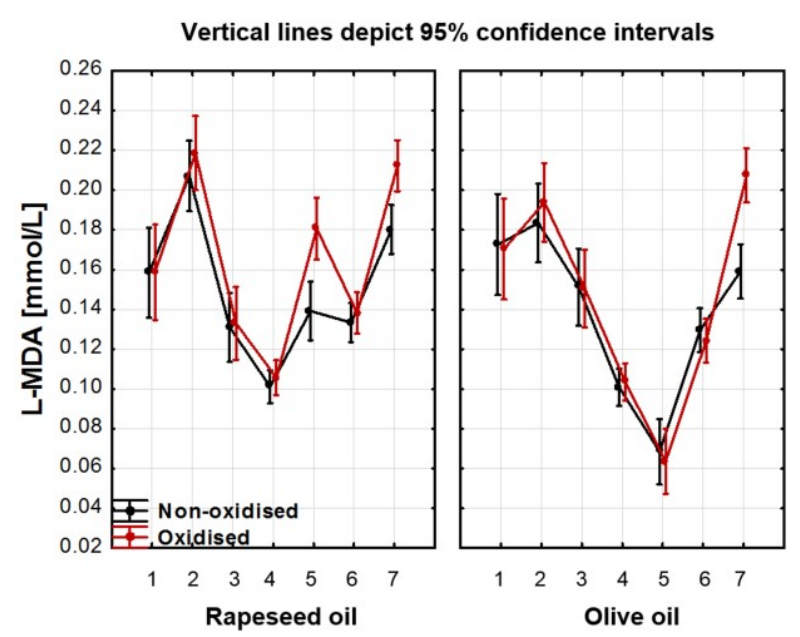

Fig. 2. Concentration of MDA in haemolysate in groups receiving non-oxidised and oxidised rapeseed oil and olive oil during experiment

\section{The activities of antioxidant enzymes and MDA concentration}

Table 1. Statistical significance levels for differences between groups receiving high fat diets with different vegetable oils

\begin{tabular}{|c|c|c|c|c|c|c|c|c|}
\hline \multirow[t]{2}{*}{ Parameter } & \multicolumn{4}{|c|}{ Comparison between oxidised and non-oxidised oil } & \multicolumn{4}{|c|}{$\begin{array}{l}\Delta_{7-1} \\
\begin{array}{c}\text { Comparison between the last (seven months) } \\
\text { and first (one month) values }\end{array}\end{array}$} \\
\hline & $\mathrm{Q}_{1}$ & $\mathrm{Q}_{2}$ & $\mathrm{Q}_{3}$ & $\mathrm{Q}_{4}$ & $\mathrm{D}_{1}$ & $\mathrm{D}_{2}$ & $\mathrm{D}_{3}$ & $\mathrm{D}_{4}$ \\
\hline S-MDA & 0.67 & 0.13 & $<0.001$ & $<0.001$ & $<0.01 \downarrow$ & $<0.05 \downarrow$ & 0.21 & $<0.05 \downarrow$ \\
\hline L-MDA & $<0.01$ & 0.14 & $<0.01$ & $<0.001$ & 0.07 & 0.31 & $<0.001 \uparrow$ & $<0.01 \uparrow$ \\
\hline S-SOD & 0.52 & 0.90 & $<0.001$ & $<0.001$ & $<0.05 \uparrow$ & $<0.001 \uparrow$ & $<0.01 \uparrow$ & $<0.001 \uparrow$ \\
\hline S-MnSOD & 0.86 & 0.88 & 0.38 & 0.37 & $<0.001 \uparrow$ & $<0.001 \uparrow$ & $<0.001 \uparrow$ & $<0.001 \uparrow$ \\
\hline S-CuZnSOD & 0.85 & 0.89 & $<0.001$ & $<0.001$ & 0.09 & $<\mathbf{0 . 0 5} \uparrow$ & 0.76 & $<0.05 \uparrow$ \\
\hline L-CAT & 0.68 & $<0.05$ & $<0.05$ & 0.47 & $<0.01 \downarrow$ & $<0.05 \uparrow$ & 0.61 & $<0.01 \uparrow$ \\
\hline L-GR & 0.99 & 0.79 & $<0.01$ & $<0.01$ & $<0.05 \downarrow$ & 0.62 & 0.18 & $<0.05 \downarrow$ \\
\hline L-GPX & 0.49 & 0.62 & 0.25 & $<0.05$ & $<0.001 \uparrow$ & $<0.001 \downarrow$ & $<0.001 \uparrow$ & $<0.001 \downarrow$ \\
\hline
\end{tabular}

Q1 - comparison between oxidised and non-oxidised rapeseed oil

Q2 - comparison between oxidised and non-oxidised olive oil

Q3 - comparison between non-oxidised rapeseed oil and non-oxidised olive oil

Q4 - comparison between oxidised rapeseed oil and oxidised olive oil

D1 - change through time (seven months $v s$ one month) for non-oxidised rapeseed oil

D2 - change through time (seven months $v s$ one month) for non-oxidised olive oil

D3 - change through time (seven months $v s$ one month) for oxidised rapeseed oil

D4 - change through time (seven months $v s$ one month) for oxidised olive oil 
SOD, MnSOD, and CuZnSOD activities
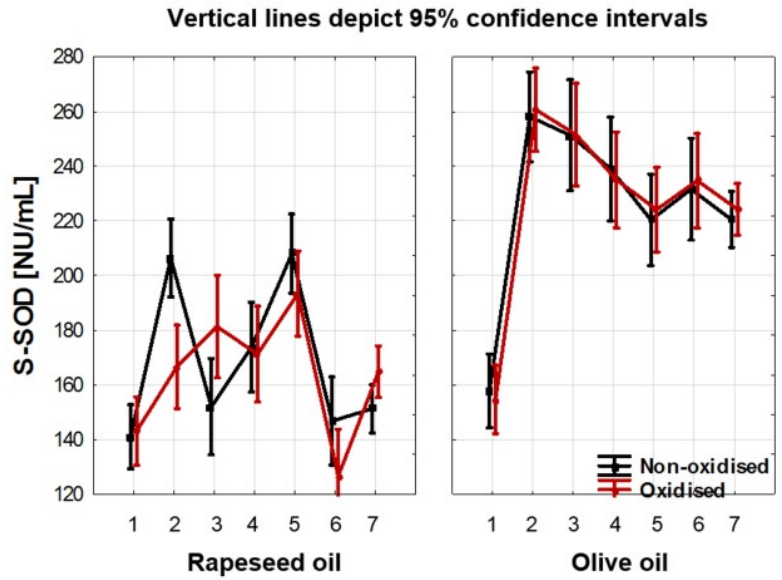

Fig. 3. Activity of total superoxide dismutase in serum in groups receiving non-oxidised and oxidised rapeseed oil and olive oil during the experiment

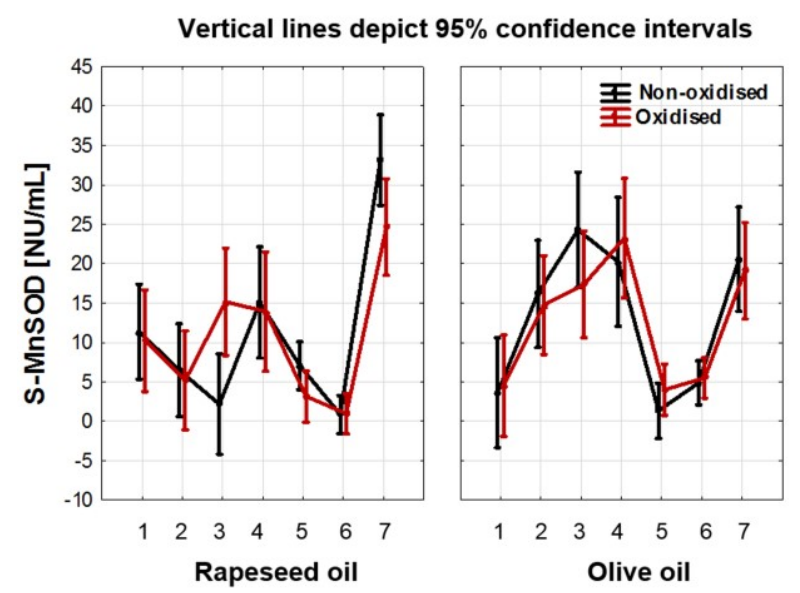

Fig. 4. Activity of superoxide dismutase mitochondrial isoenzyme in groups receiving non-oxidised and oxidised rapeseed oil and olive oil during the experiment

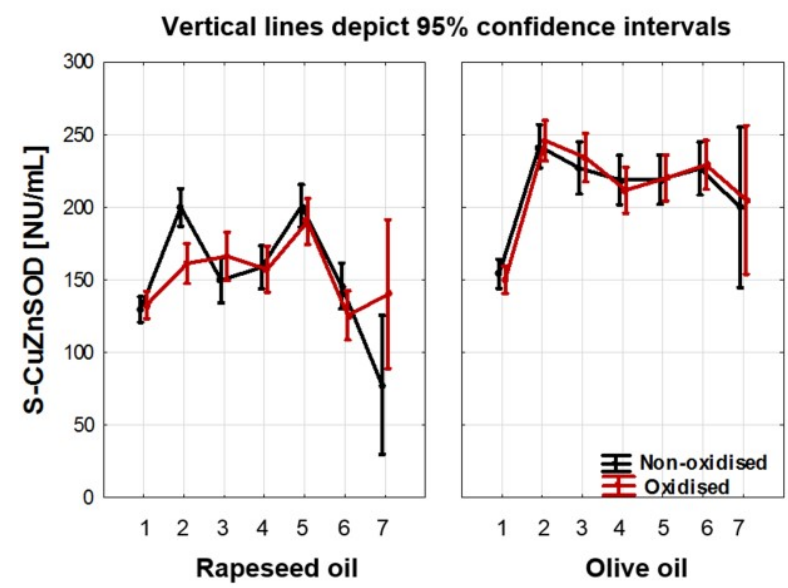

Fig. 5. Activity of superoxide dismutase cytosolic isoenzyme in groups receiving non-oxidised and oxidised rapeseed oil and olive oil during the experiment

\section{CAT, GPX, and GR activities}

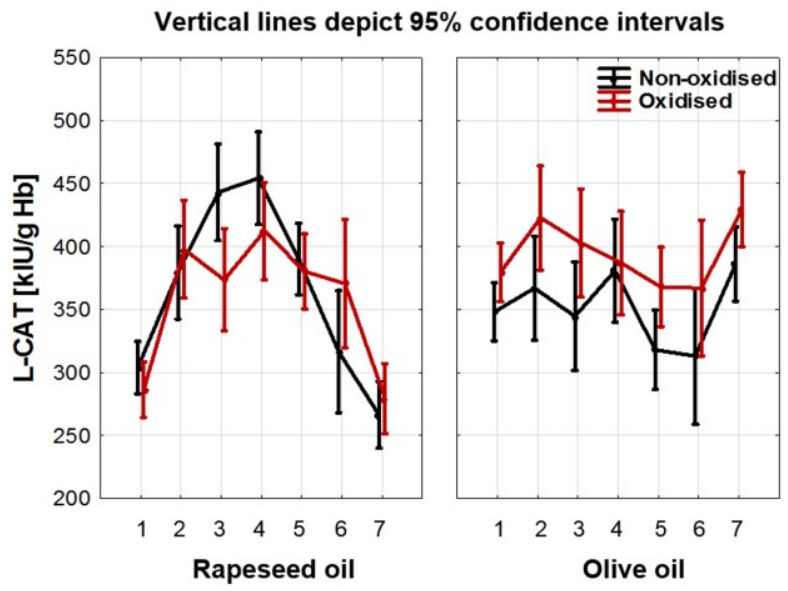

Fig. 6. Activity of catalase in haemolysate (L-CAT) in groups receiving non-oxidised and oxidised rapeseed oil and olive oil during the experiment

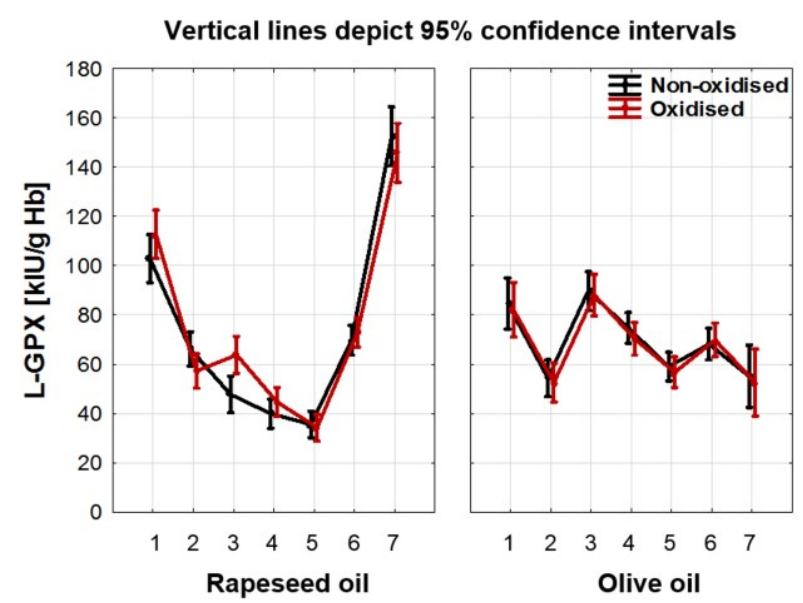

Fig. 7. Activity of glutathione peroxidase in haemolysate (L-GPX) in groups receiving non-oxidised and oxidised rapeseed oil and olive oil during the experiment

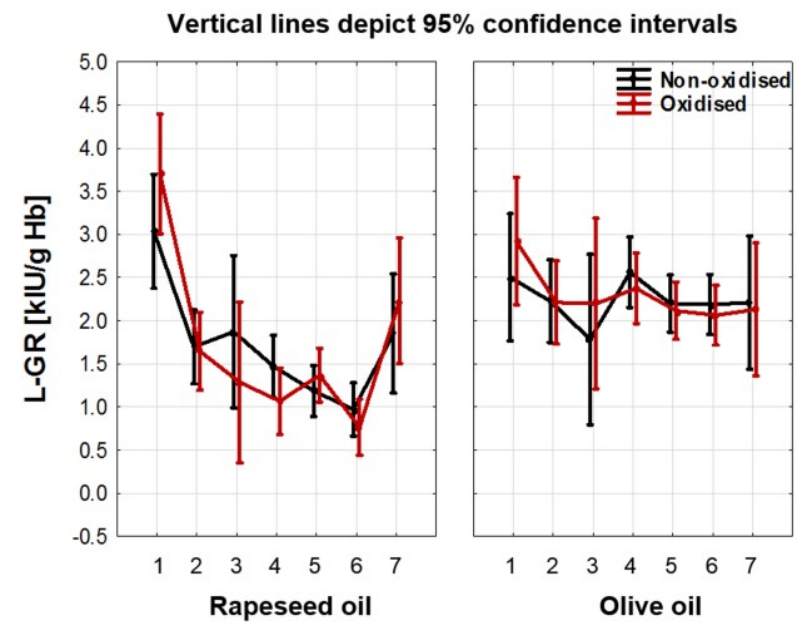

Fig. 8. Activity of glutathione reductase in haemolysate (L-GR) in groups receiving non-oxidised and oxidised rapeseed oil and olive oil during the experiment 
Figures 3, 4, and 5 present changes in S-SOD, MnSOD, and CuZnSOD activities in rabbit serum during the experiment. Table 1 gives statistical significance levels (p) for differences of SOD, MnSOD, and CuZnSOD activity among groups $\mathrm{Q}$ and $\mathrm{D}$ receiving HFD with different vegetable oil additions. There were differences between groups $\mathrm{RN}$ and $\mathrm{ON}(\mathrm{Q} 3)$ and $\mathrm{RO}$ and OO (Q4) for SOD and CuZnSOD activity $(\mathrm{P}<0.001)$. A significant increase in SOD and MnSOD activity in all groups $\left(\mathrm{D}_{1-4} ; \mathrm{P}<0.001\right)$ was also observed at the end of the experiment in comparison to the first day of the experiment. The results which follow are all in $\mathrm{NU} / \mathrm{mL}$. For SOD activity in the RN group the increase was from $131.43 \pm 18.56$ to $142.31 \pm 14.30$, in the $\mathrm{ON}$ group it was from $159.94 \pm 12.00$ to $218.37 \pm 8.36$, in the RO group from $134.50 \pm 11.28$ to $170.16 \pm 11.76$, and in the $\mathrm{OO}$ group from $153.00 \pm 12.69$ to $225.49 \pm$ 1.71. For MnSOD in the $\mathrm{RN}$ group the value rise was from $7.02 \pm 0.65$ to $35.27 \pm 4.9$, in the ON group from $3.49 \pm 0.32$ to $23.9 \pm 6.72$, in the RO group from $4.70 \pm$ 0.26 to $25.14 \pm 9.19$, and in the OO group from $4.58 \pm$ 0.38 to $14.67 \pm 6.14$.

In the case of CuZnSOD only in the $\mathrm{ON}$ and $\mathrm{OO}$ groups $\left(\mathrm{D}_{2}, \mathrm{D}_{4} ; \mathrm{P}<0.05\right)$ was there activity increase: in the ON group from $156.45 \pm 10.66$ to $194.48 \pm$ 1.81 and in the $\mathrm{OO}$ group from $148.41 \pm 11.75$ to 210.82 \pm 7.83 .

Figs 6,7 , and 8 present changes in profiles of CAT, GPX, and GR activity in blood haemolysate during the experiment. Table 1 gives statistical significance levels (p) for differences in CAT, GPX, and GR activity among groups $\mathrm{Q}$ and $\mathrm{D}$ receiving HFD with different vegetable oil additions. There were differences between groups $\mathrm{ON}$ and $\mathrm{OO}(\mathrm{Q} 2)$ and groups $\mathrm{RN}$ and $\mathrm{ON}(\mathrm{Q} 3)$ for CAT activity $(\mathrm{P}<0.05)$. For GR activity, there were differences between groups $\mathrm{RN}$ and $\mathrm{ON}(\mathrm{Q} 3)$ and groups $\mathrm{RO}$ and $\mathrm{OO}(\mathrm{Q} 4)$ $(\mathrm{P}<0.01)$. For GPX activity there was only a significant difference between groups $\mathrm{RO}$ and $\mathrm{OO}$ (Q4) $(\mathrm{P}<0.05)$. Data for all activities reported in the following are shown in international units $/ \mathrm{g} \mathrm{Hb}$ $(\mathrm{kIU} / \mathrm{gHb})$. A significant decrease was observed in CAT activity in the RN group at the end of the experiment $(265.80 \pm 21.57)$ in comparison to the first day $(298.83 \pm 35.31)$, while an increase in CAT in the $\mathrm{ON}$ and $\mathrm{OO}$ groups was observed: in the ON group from $350.57 \pm 33.44$ to $386.97 \pm 32.32$, and in the $\mathrm{OO}$ group from $372.12 \pm 18.49$ to $419.97 \pm 16.08$. A decrease was noted in GR activity in the $\mathrm{RN}$ and $\mathrm{OO}$ groups $(\mathrm{P}<0.05)$ : in the $\mathrm{RN}$ group from $2.85 \pm 1.36$ to $2.04 \pm 0.81$, and in the $\mathrm{OO}$ group from $2.79 \pm 1.45$ to $2.02 \pm 0.48$. For GPX activity, a decrease was witnessed in the $\mathrm{ON}$ and $\mathrm{OO}$ groups $(\mathrm{P}<0.001)$ : in the ON group from $87.09 \pm 5.75$ to $58.66 \pm 3.52$ and in the OO group from $81.37 \pm 5.04$ to $53.13 \pm 1.54$. An increase in GPX for the RN and RO groups was observed: in the $\mathrm{RN}$ group from $104.54 \pm 20.83$ to $156.85 \pm 6.83$ and in the RO group from $119.19 \pm$ 17.93 to $161.76 \pm 18.86$.

\section{Discussion}

This article is focused on the putative action of the reactive oxygenated species (ROS) in producing oxidative injury/oxidative stress induced by a high fat diet (HFD) rich in oxidised and non-oxidised popular edible vegetable oils. This is a very important issue as oxidative stress, defined as a perturbation of cell redox balance and an excessive production of ROS that cannot be counteracted by the action of antioxidants (enzymatic or non-enzymatic), is the reason of many diseases. This is because oxidative stress induces structure modifications and function modulation in lipids, proteins, and nucleic acids. The imbalance between the oxidant species and the antioxidant defence system may trigger specific factors responsible for oxidative damage in the cell: over-expression of oncogenes, generation of mutagen compounds, and promotion of atherogenic activity or inflammation. This may lead to cancer, neurodegeneration, cardiovascular diseases, diabetes or kidney diseases (3, $11,17)$. On the other hand, oxidative stress is a normal phenomenon in the body. Under normal conditions, the physiologically important intracellular levels of ROS are maintained at low levels by various enzyme systems participating in the in vivo redox homeostasis. Therefore, oxidative stress can also be viewed as an imbalance between the prooxidants and antioxidants in the body. This balance is maintained by the presence of natural antioxidants and antioxidant enzymes such as superoxide dismutase, catalase, and glutathione peroxidase. The enhancement of lipid peroxidation or a decrease in antioxidant protection present in metabolic disorders or resulting from bad lifestyle (i.e. consumption of HFD) can induce many dysfunctions and diseases.

At the end of the conducted experiment, a significant decrease in serum MDA concentration was observed in rabbits fed basal diet (BD) with addition of non-oxidised rapeseed oil (group $\mathrm{RN}$ ), nonoxidised olive oil (group ON), and oxidised olive oil (group OO). In case of non-oxidised olive oil consumption, a low concentration of MDA was observed throughout the whole time of the experiment, whereas in the case of oxidised olive oil consumption, the decrease was observed from the $4^{\text {th }}$ month of the experiment. In case of non-oxidised rapeseed oil consumption, until the $5^{\text {th }}$ month of the experiment an increase in serum MDA concentration was observed, but in the $6^{\text {th }}$ month the concentration of MDA decreased rapidly. In the $6^{\text {th }}$ month of the experiment there were no changes observed in the group fed $\mathrm{BD}$ with addition of oxidised rapeseed oil (group RO).

Meanwhile, in the $6^{\text {th }}$ month of the experiment, a significant increase in haemolysate L-MDA concentration in RO and $\mathrm{OO}$ groups was observed, despite the fluctuations and low concentrations of L-MDA observed from month two to month five. It proves that a diet rich in oxidised oils disturbs the oxidative 
homeostasis of an organism and results in increased lipid peroxidation. However, in the long term some stabilisation in blood serum can be expected, but not in erythrocyte. Our previous research on rats' liver and blood confirmed this observation. The concentration of MDA determined in liver homogenates and in blood plasma increased statistically significantly after consumption of a diet rich in oxidised oils $(24,25)$. Similar results were obtained during our other experiment conducted on rabbits (26). The animals were fed a balanced diet with addition of rapeseed oil oxidised for seven days at $120^{\circ} \mathrm{C}$, and erythrocyte MDA concentration increased significantly at the end of the experiment. But after six weeks a decrease in the L-MDA concentration was observed. Izaki et al. (8) reported an increased concentration of MDA in rats exposed to oxidised rapeseed oil derived from frying fish paste. The authors connected this observation with an increased content of arachidonic acid and docosahexaenoic acid in lipids isolated from the liver of the animals, as well as a marked drop in the $\alpha$-tocopherol concentration in the oil examined. Tabatabaei et al. (19) also noted that the consumption of vegetable oil oxidised for $48 \mathrm{~h}$ at $180^{\circ} \mathrm{C}$ caused a significant increase in the MDA concentration in rat blood serum.

The obtained results proved that consumption of HFD with the addition of oxidised and non-oxidised oils influenced oxidative status, most likely due to the increase in lipid peroxides concentration. This caused disturbances in the activity of antioxidant enzymes and MDA concentration, both in serum and erythrocytes. A statistically significant increase in the activity of total SOD and MnSOD in all experimental groups was also observed. Moreover, a significant increase in CuZnSOD activity in rabbits fed non-oxidised and oxidised olive oil was found. Analysis of the results leads to the conclusion that consumption of not only oxidised oils, but also non-oxidised oils in higher amounts (unbalanced diet), may cause disruption of antioxidant enzymatic systems. The increased activity of antioxidant enzymes testifies that during oxidative stress induced by HFD, this enzyme protects blood as well as mitochondria. In this experiment we also observed changes in the activity of CAT and GPX, which varied depending on the applied oils. The increased activity of GPX in RN and RO groups evidenced that GPX was the enzyme that decomposed $\mathrm{H}_{2} \mathrm{O}_{2}$ formed as a result of the SOD activity, while in $\mathrm{ON}$ and $\mathrm{OO}$ groups this role was played mainly by CAT, as we observed an increase in its activity in these groups at the end of the experiment. This proves the differences between rapeseed oil and olive oil caused by different fatty acid composition and probably by different content of non-enzymatic antioxidant. These differences are in turn the consequences of different oxidative stability of the oils used. We also observed a decrease in GR activity in the RN and OO groups.

In our previous experiment we observed that total SOD activity determined in erythrocytes was not affected by non-oxidised or oxidised rapeseed oil, with the exception of the $6^{\text {th }}$ week of the experiment, when SOD activity decreased in the group receiving oxidised oil (25). A similar observation applies to GPX activity, despite the fact the experiment was conducted under different conditions (26). Similar results were obtained in our other experiment conducted on rats (25). We observed an increase in total SOD and CuZnSOD activities and a decrease in MnSOD activity in serum of rats fed oxidised rapeseed oil. We also observed an increase in CAT and a decrease in GPX activities in the groups fed basal diet with the addition of oxidised oil. These results varied from the ones obtained in this study.

The conducted experiment shows that the consumption of HFD with the addition of oxidised oils and raw/non-oxidised oils disturbs the body's oxidative status. The diverse results obtained for the oils used in this study arise from the different compositions of those oils and hence from their different oxidative stability. This study also leads to the conclusion that both type and amount of oil, as well as the form in which it is consumed (raw or fried) affect our health. It should be noted that consumption of fried vegetable oils, especially in large amount, disrupts the oxidative status of the body and may be a cause of many metabolic disorders. However, it seems that during long-term consumption of such a diet, the body is capable of adapting to the special conditions and the enzymatic antioxidant system may still be effective.

Conflict of Interests Statement: The authors declare that there is no conflict of interests regarding the publication of this article.

Financial Disclosure Statement: The source of funding of research and the article were University funds.

Animal Rights Statement: The experiments on animals were conducted in accordance with local Ethical Committee laws and regulations as regards care and use of laboratory animals.

Acknowledgments: Special thanks to Edyta Hudziec from the Department of Biochemistry of the School of Medicine with the Division of Dentistry in Zabrze Silesian University of Medicine for her help in biochemical analysis.

\section{References}

1. Aebi H.: Catalase in vitro. Methods Enzymol 1984, 105, 121-126.

2. Attorri L., Di Biase A., Di Benedetto R., Rigato P., Di Virgilio A., Salvati S.: Micronutrient-enriched rapeseed oils reduce cardiovascular disease risk factors in rats fed a high-fat diet. Atherosclerosis 2010, 213, 422-428. 
3. Barone E., Arena A., Head E., Butterfield D.A., Perluigi M.: Disturbance of redox homeostasis in Down Syndrome: Role of iron dysmetabolism. Free Radic Biol Med 2018, 114, 84-93. doi: 10.1016/j.freeradbiomed.2017.07.009.

4. Benzie I.F.: Lipid peroxidation: a review of causes, consequences, measurement, and dietary influences. Int J Food Sci Nutr 1996, 47, 233-261.

5. Fernandez M.L., West K.L.: Mechanisms by which dietary fatty acids modulate plasma lipids. J Nutr 2005, 135, 2075-2078.

6. Fernández-Real J.M., Bulló M., Moreno-Navarrete J.M., Ricart W., Ros E., Estruch R., Salas-Salvadó J.: A Mediterranean diet enriched with olive oil is associated with higher serum total osteocalcin levels in elderly men at high cardiovascular risk. J Clin Endocrinol Metab 2012, 97, 3792-3798. doi: 10.1210/jc.2012-2221.

7. Gladine C., Combe N., Vaysse C., Pereira B., Huertas A., Salvati S., Rossignol-Castera A., Cano N., Chardigny J.M.: Optimized rapeseed oil enriched with healthy micronutrients: a relevant nutritional approach to prevent cardiovascular diseases. Results of the optim'oils randomized intervention trial. J Nutr Biochem 2013, 24, 544-549.

8. Izaki Y., Yoshikawa S., Uchiyama M.: Effect of ingestion of thermally oxidized frying oil on peroxidative criteria in rats. Lipids 1984, 19, 324-331.

9. Kurutas E.B.: The importance of antioxidants which play the role in cellular response against oxidative/nitrosative stress: current state. Nutr J 2016, 15, 71. doi: 10.1186/s12937-016-0186-5.

10. Lichtenstein A.H., Kennedy E., Barrier P., Danford D., Ernst N.D., Grundy S.M., Leveille G.A., Van Horn L., Williams C.L., Booth S.L.: Dietary fat consumption and health. Nutr Rev 1998, $56,23-28$.

11. Niemann B., Rohrbach S., Miller M.R., Newby D.E., Fuster V., Kovacic J.C.: Oxidative stress and cardiovascular risk: obesity, diabetes, smoking, and pollution: Part 3 of a 3-Part Series. J Am Coll Cardiol 2017, 70, 230-251. doi: 10.1016/j.jacc.2017.05.043.

12. Ohkawa H., Ohishi N., Yagi K.: Assay for peroxidases in animal tissues by thiobarbituric acid reaction. Anal Biochem 1973, 95, 351-358.

13. Oyanagui Y.: Reevaluation of assay methods and establishment of kit for superoxide dismutase activity. Anal Biochem. 1984, 142, 290-296.

14. Paglia D., Valentine W.: Studies on the quantities and quantitative characterization of erythrocyte glutathione peroxidase. J Lab Clin 1967, 70, 158-169.

15. Polish Standardizing Committee - Animal and vegetable oils and fats - determination of peroxide value (pp. 3-7). Warsaw, 1996:
Norm. Alfa - Wero. Polish Standardizing Committee - Animal and vegetable oils and fats - determination of iodine value (pp. 3-7). Warsaw, 1998: Norm. Alfa - Wero.

16. Richterich R.: Clinical chemistry. PZWL Warsaw 1971, pp. 359-360.

17. Saha S.K., Lee S.B., Won J., Choi H.Y., Kim K., Yang G.M., Dayem A.A., Cho S.G.: Correlation between oxidative stress, nutrition, and cancer initiation. Int J Mol Sci 2017, 18. doi: 10.3390/ijms 18071544

18. Sies H.: Oxidative stress: a concept in redox biology and medicine. Redox Biol 2015, 4, 180-183.

19. Tabatabaei N., Jamalian J., Owji A.A., Ramezani R., Karbalaie N., Rajaeifard A.R.: Effects of dietary selenium supplementation on serum and liver selenium, serum malondialdehyde, and liver glutathione peroxidase activity in rats consuming thermally oxidized sunflower oil. Food Chem Toxicol 2008, 46, 3501-3505.

20. Toborek M., Feldman D.L., Hennig B.: Aortic antioxidant defense and lipid peroxidation in rabbits fed diets supplemented with different animal and plant fats. J Am Coll Nutr 1997, 16, $32-38$.

21. Totani N., Burenjargal M., Yawata M., Ojiri Y.: Chemical properties and cytotoxicity of thermally oxidized oil. J Oleo Sci 2008, 57, 153-160.

22. Winterhalter K.: Hemoglobins, porphyrins, and related compounds in clinical biochemistry. in: Principles and Methods, Edited by Curtius M., Roth M., Berlin 1974, pp. 1305-1322.

23. Xu J., Zhou X., Deng Q., Huang Q., Yang J., Huang F.: Rapeseed oil fortified with micro-nutrients reduces atherosclerosis risk factors in rats fed a high-fat diet. Lipids Health Dis 2011, 10, 96. doi 10.1186/1476-511X-10-96.

24. Zalejska J., Wielkoszyński T., Kasperczyk S., Kasperczyk A., Birkner E.: Effects of oxidized cooking oil and $\alpha$-lipoic acid on liver antioxidants: enzyme activities and lipid peroxidation in rats fed a high fat diet. Biol Trace Elem Res 2010, 138, 272-281.

25. Zalejska J., Wielkoszyński T., Kasperczyk S., Kasperczyk A., Birkner E.: Effects of oxidized cooking oil and $\alpha$-lipoic acid on blood antioxidants: enzyme activities and lipid peroxidation in rats fed a high fat diet. Biol Trace Elem Res 2012, 145, 217-221.

26. Zalejska-Fiolka J., Kasperczyk A., Kasperczyk S., Błaszczyk U., Birkner E.: Effect of garlic supplementation on erythrocyte antioxidant parameters, lipid peroxidation, and atherosclerotic plaque formation process in oxidized oil-fed rabbits. Biol Trace Elem Res 2007, 120, 195-204. 